\title{
The Value of Research in Creativity and the Arts
}

\author{
Celine Latulipe \\ College of Computing and Informatics \\ University of North Carolina at Charlotte \\ clatulip@uncc.edu
}

\begin{abstract}
Scientists and technologists conducting research in creativity and engaging with artists face political pressure to justify their work via economic arguments. These arguments often stress how the work can lead to innovation and economic growth. This has the negative side-effect of dismissing the intrinsic value of the arts for society. The implication is that arts and creativity work that does not have economic merit is not valuable and not worthy of public funding. A case study of the NSF-funded Dance.Draw project is used to illustrate these points. I argue that a shift in dialogue is needed to focus more on the qualitative value of this work to society and less on the economic value.
\end{abstract}

\section{Author Keywords}

creativity, art, politics, value

\section{ACM Classification Keywords}

H.5.m. Information Interfaces and Presentation (e.g. HCI): Miscellaneous

\section{General Terms \\ Human Factors; Design.}

\section{INTRODUCTION}

Why do people care about creativity and the arts? When people do research in creativity, when non-profit organizations sponsor art shows or performances, or when companies develop products meant to boost creativity, how is this all sold and marketed? Why do government agencies and politicians care about creativity and the arts?

With regards to creativity, there is often no explicit rationale given - seemingly none is needed because everyone assumes creativity, whatever it means, is a 'good thing.' When a rationale is given, it is typically argued that creativity is important to society because it is the fuel for innovation and economic growth. Richard Florida promotes the idea of the 'creative class,' and the importance of making this class feel welcome in cities in order to promote economic growth and competitiveness [18]. Other reasons are sometimes given, but they

\footnotetext{
Permission to make digital or hard copies of all or part of this work for personal or classroom use is granted without fee provided that copies are not made or distributed for profit or commercial advantage and that copies bear this notice and the full citation on the first page. Copyrights for components of this work owned by others than ACM must be honored. Abstracting with credit is permitted. To copy otherwise, or republish, to post on servers or to redistribute to lists, requires prior specific permission and/or a fee. Request permissions from Permissions@acm.org.

C\&C'13, June 17-20, 2013, Sydney, NSW, Australia

Copyright 2013 ACM 978-1-4503-2150-1/13/06...\$15.00.
}

often turn out to be variations on the innovation and growth argument. Much of the academic research in creativity has been conducted in areas such as engineering and business, because, at least as far as governments and politicians are concerned, that is the 'type' of creativity that really matters.

With regards to funding of the arts and arts-based research, there is significant debate. Many people care about the arts, but still consider the arts a luxury that have no place in a government funding portfolio. Citing scarcity of resources, they argue that government funds must only be devoted to endeavors that are guaranteed to fuel the economy and that 'luxuries' such as the arts belong solely in the private sector. Others disagree, and bemoan the low levels of public funding and support given to the arts and culture and related research.

I find myself very much in the camp of people who wish to see more public funding and support for research in creativity and the arts. As an invited speaker at the ACM Creativity \& Cognition Conference in 2013, I am pleased to take this opportunity to reflect on the political challenges that face technologists like myself when working across disciplines, investigating creativity and the arts. Therefore, in this essay, I will explore the implications of value, creativity and the arts as they have intertwined in my research. In particular, I will describe and discuss the media frenzy that surrounded the federally funded Dance.Draw research project in 2010. I will use this case study as a launching point for a broader discussion of the importance of promoting, in appropriate ways, creativity and arts-based research, and the arts in general. The experiences I describe here happened in the United States, where I am a faculty member at a comprehensive, state-funded, urban research university. Thus, the details of my story are necessarily US-centric. However, I believe that similar battles are being waged in other places and I hope that academics worldwide will relate to and find value in this discussion.

\section{THE VALUE QUESTION IN CREATIVITY AND THE ARTS}

How and why should we value creative endeavors and research into creativity? And in particular, how and why should we value the arts, be they visual arts, music, dance, theater or other forms? Science and technology is privileged [1] and the arts are underprivileged, as witnessed by the incredibly vast difference in funding between arts and science, creating an uneven distribution of academic and economic power. The US National Endowment for the Arts (NEA) had an annual budget of $\$ 146$ million dollars in 2012 [38], while research and development funding for US agencies including Defense, NSF, NIH, and USDA totaled more than \$140 billion dollars [40]. This means that federal arts funding is equal 
to $0.1 \%$ of federal R \& D funding in the US.

Where such an uneven power dynamic exists, it is important to examine closely the values at play and ensure that interdisciplinary work does not further deepen the privilege of science and technology at the expense of arts and humanities. If we as technologists want to work in creativity and the arts, how do we appropriately frame that work in order to highlight the value of the arts, and make sure that we do not do more harm than good? Perhaps we should create a 'hippocratic oath' of sorts for engaging in work with the arts. At a minimum, we need to increase awareness about how our arguments in support of this work actually impact the artists and arts in general. In this section, I outline the main arguments that can be made in support of funding arts and creativity research.

\section{The Qualitative Value of the Arts and Creativity}

When artists are given support to work in their communities, the value to the individual, to the community and to society is multi-faceted, but often difficult to measure numerically. The following list outlines a few of these qualitative benefits that accrue to the individual, the community and to society as a whole when artists are supported and creativity is enhanced. For an exhaustive account of the intrinsic benefits of the arts, see "Gifts of the Muse" [33].

- The ability to be creative in one's activities provides personal meaning, intrinsic motivation to succeed, and determination to face challenges [14].

- The ability to engage creatively with others in facing complex problems offers hope in solving important local and global issues, such as sustainable development, social and economic injustices, etc. [23].

- The arts provide needed critiques of current events, technological advancements, social phenomena and politics.

- The arts provide a history of our culture, so that we can understand where we are coming from and the effects of our past actions, both individually and as societies $[17,5]$.

- The arts give individuals and communities a way to envision the future, based on the current situation, allowing meaningful reflection and analysis [16].

- The arts give individuals and communities a mechanism to cope with difficult situations [43].

- The arts provide a forum that brings people together in conversation, helping to form tighter communities, which is especially important in today's gadget-driven society [48].

- The arts give us pleasure and celebrate our humanity.

The above benefits are not easy to quantify, but centuries of aesthetic philosophy has provided evidence of their power [25]. And, just because something cannot be quantified does not signify a lack of value. Given the increased quantization of everything in our society, this is an important point to remember. Quantization is one of the dimensions that gives science its privilege, but there are other ways of knowing.

While the benefits listed above are all real and important, they are not the reasons typically given for funding or supporting

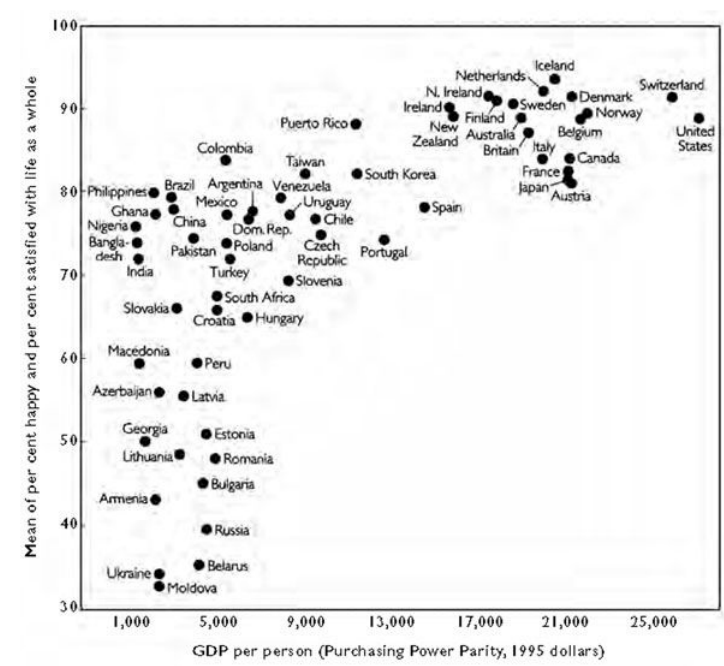

Figure 1. The relationship between mean GDP and the average level of happiness and life satisfaction around the world. The decreasing marginal returns are evident, showing that for developed nations even large increases in GDP are no longer leading to increases in happiness and life satisfaction. (c)Tim Jackson

work in the arts or research in creativity. The next sections outline the usual arguments.

\section{The Economic Growth Fallacy}

Economic growth is the underlying, driving force that is implicit in most public policy and in much private policy as well. The idea is that economies need to continue to grow at particular rates per year in order for the economy to sustain itself. The deeper, oft-unstated assumption is that a growing economy makes for a happier society and happier individuals within that society. However, there is continued growing evidence that the link between societal well-being and economic growth has broken for developed countries - increases in GDP are no longer leading to increases in happiness [22]. To justify research on creativity or interdisciplinary work with the arts by noting that it could lead to economic growth may be convincing to some, but if that is the basis for social impact in the developed world, it is a poor basis indeed.

Figure 1 shows that increases in GDP are no longer significantly adding to subjective measures of well-being for the average citizen in developed countries [22]. The situation is different in the under-developed countries, where increases in GDP mean more access to the essentials for life. If an argument is made that creativity and arts are important because they can help improve GDP in the under-developed countries, that would be worthy of consideration. However, the argument is usually that creativity is important in order to increase the competitiveness of a nation in the global, developed economy. Alternatively, one might ask, for citizens in developed countries, if economic growth is not going to improve individual well-being, what is? For countries in Figure 1 such as the United States, Japan, Canada, Italy and Austria, where the GDP per person is already high, what can be done to increase the percentage of the population that is happy and satisfied with life? While there are likely a number of possibilities, 
one is clearly to promote and fund the arts, as new research is linking arts-related activity to happiness [31].

Various researchers have also made the argument that a shift in focus from economic growth to sustainable (steady-state) economics is critical. They argue that industrial civilization may begin to collapse in the next half-century, just as previous human societies flourished and collapsed [44]. This argument is often made with reference to the finite resources on the planet, and the expectation that increasing populations and economic growth will lead to increased tensions over scarce resources. Tomlinson et al. argue strongly that HCI researchers have a role to play in preparing society for the results of such a decline [47]. If they are correct, a focus on creative solutions for dealing with ecological and societal collapse may be a much more warranted argument. Creativity and the arts will be needed to help individuals and communities cope with economic and social decline.

\section{The Value Reduction Trap}

Even if you do decide to buy into the economic growth fallacy, or just decide that it is not your fight, there is yet another trap to be aware of when promoting interdisciplinary work in creativity and the arts. Imagine you are asked to defend taxpayer spending on interdisciplinary projects that involve the arts and creativity, and you defend this investment by making the economic or business case argument along these lines:

- The arts are an important part of the economy, generating $\mathrm{X}$ million units of revenue in state/city/country $\mathrm{Y}$.

- The arts and creative work lead to new innovations that spur on economic growth.

- The arts make a city a desirable place to live (read property tax revenue) and do business (read business tax revenue).

This is the value reduction trap: these arguments limit the discussion of the value of arts to their economic factor and to their impact on innovation and economic growth. The unstated implication is that only those art projects that lead to economic activity are valuable, and any art that does not fit that category is not valuable. Critiques of Florida's 'creative class' recipes for urban economic success have made note of this reductionism in his work $[19,36]$. In a similar vein, research on creativity that is about promoting personal creativity and individual flourishing is considered unimportant because it does not (directly) impact GDP. These arguments do a disservice by vastly under-valuing the qualitative benefits of the arts and personal creativity. These arguments also exert a restrictive force that limits creativity, as the arts that tend to generate the most revenue in ticket sales are those which are established and conservative, rather than avant-garde and highly creative. We must reframe the debate and promote the intrinsic benefits of the arts [33].

In the next section, I will describe the large, interdisciplinary arts and technology project in which I was the primary investigator. This project illustrates the innovation that can come from the arts, but more importantly, the qualitative benefits of such interdisciplinary work. The media attacks on the project demonstrate the potential political land mines that are inherent in this type of work.

\section{THE DANCE.DRAW PROJECT: A CASE STUDY}

The Dance.Draw project was funded by the National Science Foundation (NSF) CreativeIT program from 2009-2013, but was supported through the American Recovery and Reinvestment Act (ARRA, commonly referred to as the 'stimulus package'), rather than through regular NSF budgetary monies. This distinction will turn out to be significant. The research project comprised three main research goals:

- To investigate low-cost, non-cumbersome technologies for simultaneously tracking in real-time the activity of multiple dancers in a space, Figure 2.

- To investigate technological innovations for audience engagement with live performances, Figure 3.

- To investigate technological support for the collaborative production of arts performances, Figure 6.

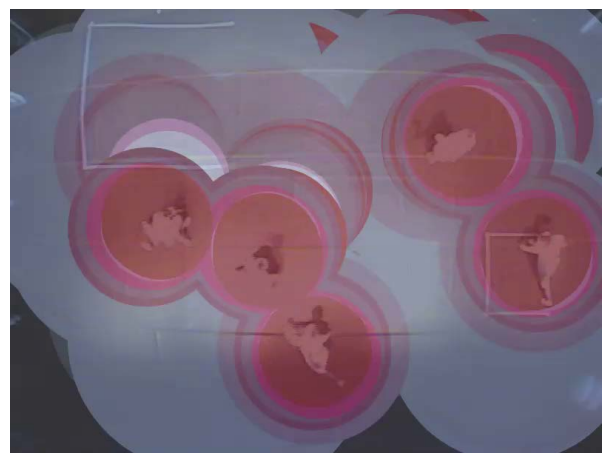

Figure 2. The dance, "Heavy Recursion," choreographed by Melissa Word, involved tracking of multiple dancers using an inexpensive security camera. The circles projected on the screen are interlaced with video feed of the dancers, and follow the dancers in real time.

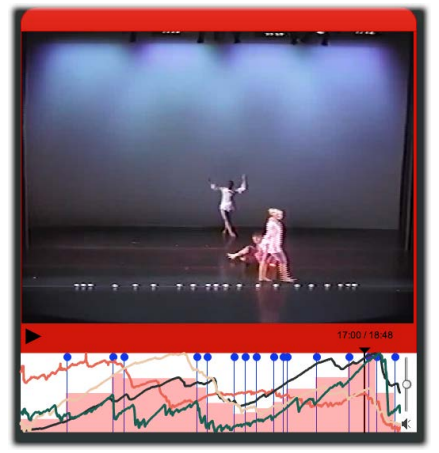

Figure 3. A specialized video player developed to allow theater directors and choreographers to analyze audience engagement as measured through galvanic skin response, in the context of the performance video.

As with all ambitious, multi-disciplinary research, we were more successful with some goals than with others, and the research changed and adapted as the computer scientists engaged more deeply with the choreographers and dancers and developed a fuller understanding of the technological needs and opportunities in dance. Some of our biggest successes were in dance productions choreographed by Sybil Huskey, Melissa Word and David Ingram that were sublime in their combination of technology and human movement [30, 28]. Another success was in our contributions in understanding 
more deeply the physiological manifestations of audience engagement in performance [10, 27]. We also reflected in a variety of venues on the process of interdisciplinary research and what we learned throughout the project $[9,26,29,20]$. Our most important technological contribution was in the development of the Choreographer's Notebook software: a webbased system for small-group collaboration around video artifacts [41]. Finally, we spent significant time developing and validating a measure to evaluate creativity support tools, such as those developed as part of the project [8].

\section{Dance Productions}

Over the course of the project, we staged seven different interactive dance pieces. I will highlight two of these dances as they relate to the qualitative arguments made earlier.

\section{Bodies/Antibodies}

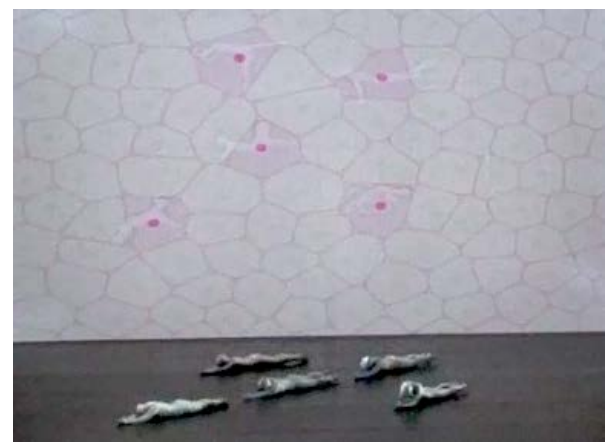

Figure 4. "Bodies/Antibodies" explores the body's immune response.

Bodies/Antibodies was choreographed by Melissa Word, with technology developed by myself, David Wilson and Nathan Nifong [30]. It explored the cellular processes through which we fight infection and disease. This dance was choreographed before the project began and then adapted and restaged twice as part of the project, using two separate tracking technologies. This dance was seen by over 1200 people in its various incarnations, and is striking because of the creativity of body movements and use of narrative and space. The interactive Voronoi visualization that was controlled by the dancers' movements was almost as engaging as the movements themselves, transporting audience members into a crowded, erratic plasma of cellular goo (Figure 4). Survey results for this dance indicated a high level of engagement with both the movements and the visualizations. The ability of this dance to really engage the audience in a question of biology was remarkable. Bodies/Antibodies also provided a new, visual and kinetic perspective for those coping with personal or family illness.

\section{SoundPainter}

The SoundPainter dance was choreographed by Sybil Huskey and Melissa Word [28]. SoundPainter is an algorithm developed by Nathan Nifong to visualize sound, which we adapted for several of our productions. In the SoundPainter dance, we used camera tracking to track the positions of the three dancers in space, and the sound painting was projected behind and followed the dancers, responding to their sounds as well as a live percussionist (Figure 5). In addition, the dancers

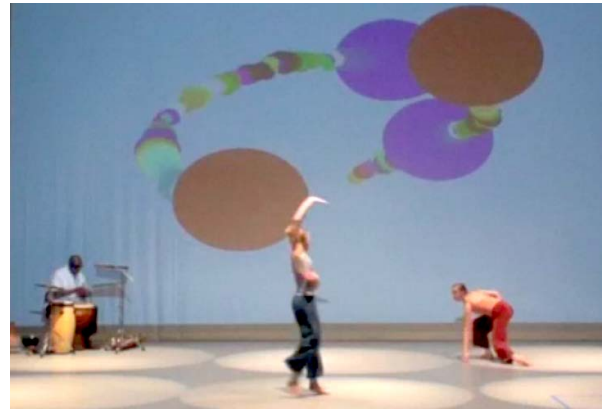

Figure 5. "SoundPainter" is improvisational play with space and sound.

were given control of a sub-space, which when entered, allowed engagement data from the audience to be explicitly visualized on the projection. Audience engagement data was captured in real-time via galvanic skin response sensors worn by audience members. The SoundPainter dance was novel in its explicit use of audience biometric data as a method for strongly engaging the audience in the playful exploration of sound and space. It implicitly asked the audience to guess the mapping between sound and visual pattern, but then reflected the audience's engagement back at them. One of the findings from the many surveys we deployed during the project is that a majority of audience members enjoy the challenge of trying to figure out the use of technology in interactive dances [26]. This demonstrates that the curious mind is joyful when fed.

\section{The Choreographer's Notebook}

Our initial plan for developing tools to support the collaborative design of dance was to create a YouTube-like application that would allow the public to replay and reconfigure our interactive dance performances. However, we realized early in the project that the choreographers and dancers needed a tool for private collaboration and so we instead built a webbased tool that allowed choreographers to upload videos from dance rehearsals, and annotate them with color-coded annotations. The system, called the Choreographer's Notebook (ChoNo), was built by my doctoral student Vikash Singh, and is shown in Figure 6. Dancers can log in to the system, view the rehearsal annotations and instructions in the context of the dance video, and add their own annotations or questions, also in context. Over the course of the Dance.Draw project, this tool has continuously iterated and has been used by over 60 dancers and 5 different choreographers.

Our choreographers, Sybil Huskey, Melissa Word and David Ingram, have told us that the ability to communicate easily and deeply in context around a video artifact has meant that they spend more time outside of rehearsal annotating and analyzing dance videos, which means there is more time during rehearsal for dancing and a higher level of performance when the dance is finally staged. The tool also allows the choreographers to stay in communication with dancers while traveling. As the developers of this technology, we are enthusiastic about these types of benefits, in particular, the enhancement of the art form, however, we are very aware that these benefits come at a cost to the work-life balance of our users. Does spending more time in order to make a better dance enhance 


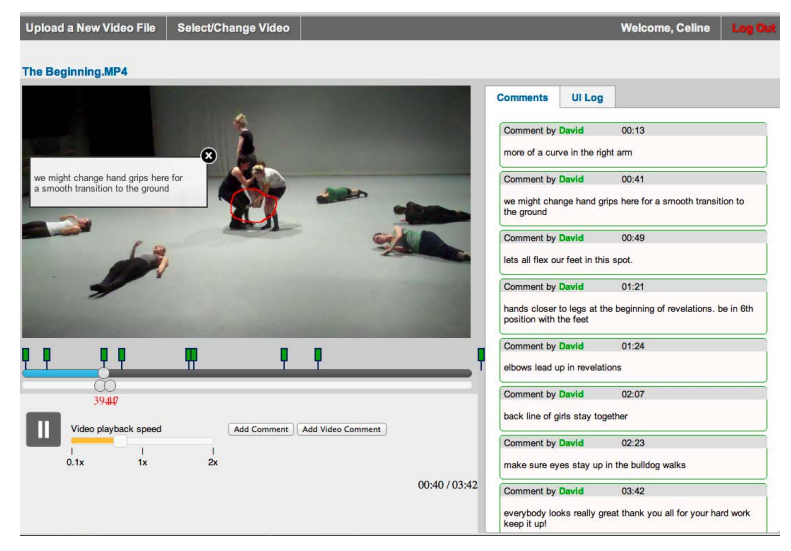

Figure 6. Sketch and text annotations in Choreographer's Notebook.

the personal creative potential of our users - does it make them more happy, or are they less happy because we have given them a way to work longer hours?

In 2012, we began to receive inquiries from people in other domains who wished to use the tool for purposes completely unrelated to dance. Because the system clearly has uses beyond dance and other performing arts, we are in the midst of rebranding the tool as 'The Video Collaboratory'. We believe that this system will prove to be very useful in research, sports, physiotherapy and education.

These examples, and our continued development of this system, demonstrate that technological innovation can stem from working with artists. This is the argument for funding of interdisciplinary research that is most easily accepted in corporate and political circles because it fits the narrative of the need for innovation and economic growth. In particular, the example of the choreographers getting what amounts to 'increased productivity' out of the dancers because they are expected to do more dance work outside of the studio, and the time spent in the studio is thus more 'efficient' is an argument that sells well. This is seen as the type of productivity boost that could be useful in other domains. Though this argument is easy to make, by making it, I fall into the economic growth fallacy discussed above, and I further imply through value reductionism, that interdisciplinary research with the arts is only valuable if it leads to this type of innovation with economic or productivity payoffs.

What is most beneficial about the Choreographer's Notebook is that it allows artists (choreographers and dancers in our case) to more deeply explore and communicate about their art. Through the tool, we have enabled a personal flourishing of these individuals as they work with each other and with their art form. The choreographers and dancers have told us that the tool allows for more individual coaching and attention than is possible during a dance rehearsal. The tool allows dancers to see their own artistic progression throughout the rehearsal process. It gives the choreographers a space to reflect and discuss their ideas about the work with each other, and with the dancers. And in the end, all of these benefits lead to a better final performance, which is capable of engaging an audience deeply. These qualitative benefits are more difficult to measure, but they are real. Our choreographers do not want to choreograph without the tool.

\section{Creativity Support Measurement}

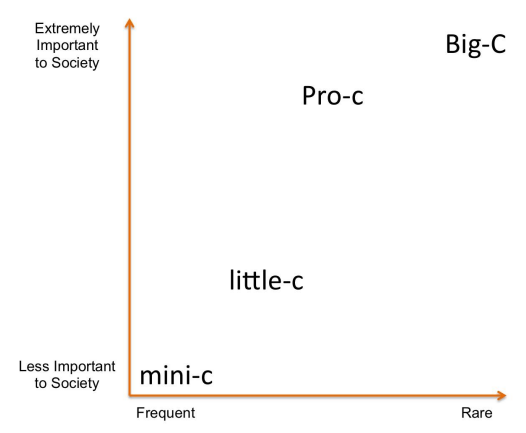

Figure 7. The creative contribution space.

Another product of the Dance.Draw research project is a survey tool called the Creativity Support Index (CSI) [8] and a new approach for classifying moments of high creative experience of an individual [10]. This work was conducted by myself and Dr. Erin Carroll, who was my doctoral student. The CSI is a psychometrically validated self-report survey that can be administered to users of a digital creativity support tool. The survey includes agreement statements relating to six component factors of creativity: exploration, expressiveness, enjoyment, collaboration, immersion and results worth effort. The survey also has comparison questions that determine which of these factors is most relevant to the creative activity the user is engaging in, and these weightings are then used to calculate a final CSI score out of 100. A higher score indicates better creativity support of the tool being assessed.

In the process of formulating the CSI, Carroll and I had many discussions around the issue of 'ground truth' in creativity. Creativity is often recognized in hindsight, when a particular artifact or invention is seen as having been a novel development that has had a significant impact on society. This is often referred to as Historical Creativity [2] or Big-C creativity [14]. Figure 7 shows a creativity contribution space, in which the different types of creativity are arranged in terms of their contribution to society and their relative rarity. The rarity of $\mathrm{H}$ or Big-C creativity means that using the existence of these contributions as evidence that a system or tool supports creativity is unlikely to be effective. But, caring only about $\mathrm{H}$ or Big-C creativity (rather than personal types of creativity: mini-c, small-c and pro-c [24]) is also problematic. It feeds into the notion that we should only care about the creativity that leads to large-scale impacts through scientific innovation or economic growth.

The goal is to support users of a creativity support tool in reaching a state of flow [15], to enhance their creative process, to allow them to flourish as individuals pursuing a creative task. In a similar vein, our work in studying the temporal aspects of the individual creative experience through measurement of In-The-Moment-Creativity (ITMC) is aimed at enhancing the creative experiences of individuals. In ITMC, we aim to detect the temporal periods during a creative work 
session when the user experiences high creativity. Our initial work in this area allowed us to build individual classifiers that detected periods of high creativity (as labeled through self-report) with $72 \%$ accuracy [10]. The motivation behind this work is to be able to better research the environmental and system factors that help keep people in a creative state of flow for longer periods of time, or conversely to prevent them from prematurely dropping out of a state of creative flow. Our assumption is that individuals will flourish when they are able to be creative for longer periods of time.

\section{The Media Ambush}

In early 2010, leading up to the 2010 mid-term US elections, a North Carolina conservative think tank, called The Civitas Institute, published a report titled: "Hot Flashes, Dead Bugs, and Cocaine for Monkeys: The 10 Worst Federal Stimulus Projects in North Carolina" [4]. The most expensive project listed on the report was our Dance.Draw project, and the description in the report read: "This grant to UNC-Charlotte will fund the development of computer technology to digitally record the dance moves of performers. The recorded movements can then be reviewed and manipulated by a computer program. Although creating virtual-reality type technology for dance movements may be interesting to those involved, how does this serve to protect the education of our children? At an average salary of roughly $\$ 47,000$, this money could have saved 16 North Carolina teacher jobs."

In March 2010, the local NBC news station contacted the University, asking to do a 'feature piece' on the Dance.Draw project, telling the university public relations staff that they were very excited to highlight the project. On March 26th, the news reporter and his cameramen arrived to film our dancers, getting very up close and personal for almost an hour, and then asked to interview me, as the the project director. They began by asking me a few clarifying questions about the project. Then came the ambush. They asked me if I knew that our project had been named one of the top-10 worst federal stimulus-funded projects in the state. I had no warning, and they had not informed the public relations people of the report's existence or that this was the real reason behind their interest in the project. They spent the next 15 minutes demanding that I justify taxpayer spending on 'dance' or the arts in general. The reporter had assumed that I was a dancer, and was surprised to find out that I was a computer scientist.

Despite being ambushed and unprepared to answer such questions, I could see the corner that the news reporter was backing me into. He wanted me to say that the project was not about art, that it was really about computer science. But this ambush was playing out in a dance studio, with the choreographers and dancers watching the entire interview unfold. It would have been a vast betrayal if I had said to the reporter, 'yes, you're right - this is really a computer science project, not a dance project and that is why it deserves funding,' because such a statement would have devalued dance, implying that funding dance, or the arts in general, is not worthy of taxpayer spending. Instead, I very specifically stated that this project was a true interdisciplinary project between dance and computer science. In particular, I remember saying some- thing like: "The arts are essential for society. They allow us to critically reflect on where we are and where we are heading. Without the arts to help us reflect on our society, we'll drift aimlessly."

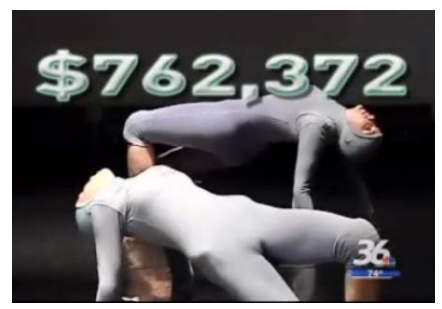

Figure 8. The photo of Dance.Draw dancers used in the NBC news story and also used in the report by Senators Tom Coburn and John McCain.

What aired on the local NBC station was, of course, cut and edited, and only the parts of the interview where I discussed the technological innovations coming out of the project aired, not the parts of the interview where I defended the value of the arts [39]. The reporter likely felt that he was doing us a favor by showing the parts of the interview that highlighted the technological innovations from the project, rather than any defense of public spending on the arts. So, even though I was aware of the trap and tried very hard to avoid focusing on the technological innovation at the expense of devaluing the artistic contributions, the news editor forced me into it. The news report was also accompanied by a photo from our dance rehearsal, consisting of a close up of two of our dancers' bodies in an out-of-context, seemingly provocative pose, with the cost label ' $\$ 762,362$ ' superimposed, suggesting that somehow we were spending this money to create lewd or morally objectionable dance (Figure 8). The dance in question, "Bodies/Antibodies" was about cellular processes within the body and had no provocative or controversial content.

In August of the same year, Republican Senator Tom Coburn and Republican Senator and recent Presidential Nominee John McCain released a report titled: "Summertime Blues: 100 stimulus projects that give taxpayers the blues" [12]. This report rank ordered the stimulus projects in terms of the egregiousness of taxpayer waste, according to some unidentified criterion. Our Dance.Draw project was listed as number two, second only to a project that installed new windows on an outof-operation visitor center at Mount St. Helens. This report contains no real analysis of any of the stimulus projects, but is dripping with sarcasm. Regarding the possibility of webbased collaborative analysis of dance performance, the report states: "One day, dance performances may enjoy the popularity of YouTube hits like 'double rainbow' or 'dramatic-look prairie dog'." The release of this report led to more media attention, including a piece on CNN [13].

\section{Analysis of the Attack}

It is a fair question to ask how this project got funded, as it is to ask about the process for all government spending. We sent our proposal to the NSF's CreativeIT program before Obama had announced the stimulus package. Our proposal went through the normal channels of NSF peer review (which are currently under attack in the US [34]). We did 
not apply for stimulus funding, and we did not anticipate that our project would be funded with stimulus monies. It is also a fair question to ask how the NSF went about deciding, of all the competitively-ranked projects that the program managers wanted to fund, which should be funded with stimulus monies and which should be funded with their normal budgetary allocation? NSF staff have provided two different responses to this question: that the decision was based on a lottery, and that the program managers picked projects which they thought would align nicely with the goals of the stimulus package. I was reassured that it was NOT the case that the best projects got normal funding and the next best projects got stimulus funding - that would have generated a stigmatized, tiered funding division that the NSF wanted to avoid. To its credit, the NSF released a brief statement in response, citing support for our project.

In addition to the obvious political backdrop that motivated this negative media attention, there are flaws and contradictions in the attacks. While the media portrays the American Recovery and Reinvestment Act as having been a 'jobs stimulus package,' it actually dictated a variety of funding, in particular for science. The opening statement of the ARRA bill [49] reads: "An act, making supplemental appropriations for job preservation and creation, infrastructure investment, energy efficiency and science, assistance to the unemployed, and State and local fiscal stabilization, for the fiscal year ending September 30, 2009, and for other purposes." Further, in section HR 1-17, under the title of Science, and the subtitle of the National Science Foundation, the legislation allocates: "For an additional amount for Research and Related Activities, $\$ 2,500,000,000 \ldots$. . This is clearly a privileging of science, and there is no particular emphasis on the arts of any kind. However, it is not purely about job creation, either.

The statement by the author of the Civitas report, contending that the money spent on the Dance.Draw project could have been used instead to fund 16 North Carolina teacher jobs, is particularly insidious. Funding of public school teachers is under the control of state budgets, not federal allocations, so it is ridiculous to suggest that the money could have been spent on public school teachers. And, much of the money for the grant was spent on public education: UNC Charlotte is a state university, and $44 \%$ of direct costs in the proposal budget went to university overhead, which funds programs and infrastructure to serve the interests of the university.

\section{DISCUSSION}

Our Dance.Draw project is not the first project and will not be the last project in HCI or interdisciplinary arts-related research to face media scrutiny. A recent publication at the ACM CHI conference analyzed a few HCI research projects in the UK that actively tried to harness the power of the media. Their grounded theory analysis of the media coverage and public reaction to these research projects showed that there are significant problems with media outlets skewing the work and with public misinterpretation of the work [50].

Beyond the general citizenry, elected (or unelected) politicians are also unqualified to make such judgements. Agencies such as the National Science Foundation were created as independent agencies specifically to prevent politicians from meddling in research and specifically to ensure that government funding of research was conducted through academic peer review [3]. Yet, there is a long history of such political judgements; the most well-known of which is Proxmire's Golden Fleece awards [21]. Proxmire was a Democratic Senator who began to publicly berate federally-funded projects that he considered wasteful, awarding these projects the 'Golden Fleece Award' [51], the first of which went to the NSF in 1975 for funding a study on why people fall in love.

The reality is that academic researchers need to be prepared to explain their research to the media, knowing that the media serves as a filter to the information that is disseminated to the public. If you are an academic researcher, consider what you might do to justify your research if the amount of your funding was broken down into how many public school teacher jobs it would fund. The privilege of science means that researchers in engineering, science, medicine, and computer science do not often have to answer to such scrutiny. The economic growth fallacy has served to protect science and helps to boost its privilege. The arts and the humanities, typically underfunded research areas, are constantly being asked to justify their existence on university campuses, and to justify what little taxpayer money they do receive. In a recent debate forum on the Huffington Post, an online liberalleaning news site, readers were asked to discuss "Is Federal Money The Best Way To Fund The Arts?" [45]. Given that federal arts funding in the US is equal to $0.001 \%$ of federal $\mathrm{R} \& \mathrm{D}$ funding in the US, one wonders why it is even worth discussing. The debate should be: "Why aren't we funding the arts better, given their value to society?"

The other historical event that is particularly relevant to the politicization of funding in creativity and the arts is the 'Piss Christ' controversy in which Serrano's photograph of a plastic crucifix submerged in urine led to US Senators lobbying successfully for funding cuts and restrictions on the NEA [35]. The frenzy that followed this controversy, in the US and in Australia, was intense, and led to public discussion of whether politicians and taxpayers should decide what constitutes art. This discussion parallels the issue of whether the public and politicians should decide what research is fundable. In both cases, the current political environment suggests that researchers are going to have to continue to justify research in the arts and creativity.

\section{The Defensive Playbook}

One could argue that anyone should be able to justify, at a high level, the work that they do. And potentially, when taxpayers are footing the bill, there is a stronger imperative for justification. But, to whom should we justify our research? There is a fine line to be tread between the notion of public accountability and public judgement. While we all want taxpayer money to be spent wisely, we also need to acknowledge that the majority of the public is not educated enough to be able to assess the value of proposed research, whether in the arts or the sciences, or an interdisciplinary mix. This is not to deride the intelligence of the public, it is simply the case that research is highly specialized. Most of my colleagues, despite 
their doctoral degrees and the high level of education they have achieved, would not consider themselves well-informed enough to judge the merits of projects outside their particular field of study. If we only feel well-informed enough to judge research projects in our own field, we shouldn't expect citizens in the general population to be able to effectively make such judgements. That is why in 1945, Vannevar Bush recommended to Roosevelt that federal research funding be allocated through a system of peer-review, coordinated by agencies independent of the political party in power [6].

The Civitas report's comparison to the number of school teachers that could be hired is particularly offensive considering that the Civitas Institute has been a strong proponent of private school vouchers and 'school choice,' (a plan to help parents pay for tuition for their children to attend private schools, which would likely undermine the public school system [32]). The comparison is an attempt to commodify the arts, which really cannot, and should not, be commodified. This type of tactic is designed to surreptitiously build public support for defunding the arts. It is because of conservative agendas such as this that a true defensive strategy for funding arts-related research may require sneaking the arts in under the disguise of privileged science.

The money that funded the Dance.Draw project was allocated to the NSF. It would not have gone to support state resources for teachers if the Dance.Draw proposal was not funded. It would have gone to fund other research in a different part of the country. The overhead that goes to the University supports the university system and this is the main way that the Federal government supports higher education, through the competitive mechanism of grant proposing and funding. These are the arguments that the NBC reporter wanted me to focus on. While valid, they do a disservice by not fully acknowledging and respecting the value of dance.

If you feel the need or are forced to play this purely defensive game in writing arts-related funding proposals, or in dealing with the media, here are some tips:

- Avoid using arts related words in your proposal title, and hide the art deep in your proposal narrative.

- Emphasize the quantitative and statistical methods you will use. De-emphasize the critical study methods, interpretive analysis and aesthetic artifacts in your work.

- Make sure that you show explicitly how any arts-related project will lead to technological innovation and therefore the potential for economic growth.

- Repeatedly stress the science in your arts-related work. Remember that science has privilege.

Clearly, I don't like playing the defensive game, though I have sometimes been forced into it. I liken the list above to the lists that are provided to women as advice for prevention of rape - don't wear short skirts or go out late at night, etc. [46]. Women should have the freedom to live their lives and dress the way they want to [37]. Likewise, researchers should have the freedom to be honest about the kind of research they are proposing, and where the real value in the research lies, without fear of political attacks if the proposal is funded or fear of funding denials due to the arts component of the research.

\section{The Offensive Playbook}

It is sometimes said that the best defense is a strong offense. What we really need to do as scientists working in the areas of creativity and the arts is promote the qualitative values of this work in a way that fully respect the arts. In that spirit, I humbly offer the following suggestions:

- Recognize and acknowledge your privilege as a 'scientist.' Speak up to point out this privilege when colleagues deride qualitative work or arts-based research.

- Seek opportunities to work with artists.

- Hire arts students to work with you on your research.

- Include requests for an artist-in-residence in your grant proposals. Hire an artist-in-residence at your university.

- Ask for artists to be on your proposal review panel.

- Stress the value of artistic collaborations and contributions in your grant proposals, when dealing with the media and in your teaching and mentoring.

- Allow artistic and qualitative as well as technological and quantitative projects in your classes.

Rather than waiting to be attacked by politicians, we should be proactive in telling politicians what we value and expect from them with regard to creativity research and the arts. Counter-offensive rape advice lists offer potential rapists tips to prevent rape from happening, such as: "When you encounter a woman who is asleep, the safest course of action is to not rape her" [7]. In this spirit of what should be obvious, I offer this advice to politicians:

- Don't use researchers and artists as political fodder.

- Promote the value of the arts, humanities and creativity as a critical way to improve society and individual well-being.

- Trust the funding agencies and the peer review process and convince your colleagues and voters to do the same.

- Promote a flourishing society by supporting basic research funding in arts and science with public funds.

\section{Beyond the US}

The overuse of the economic impact and economic growth arguments and the under-valuation of the social impact of the arts is not restricted to American soil. For example, a recent report from the Arts Council of England celebrated that significant return on investment gained from the tiny amount of federal funding on the arts [11]. And Maria Miller, UK Secretary of Culture, recently insisted that the arts must be judged by their economic value [42]. Governments around the globe contend with scarce resources, and often the first areas to suffer cuts are the arts, because they have been commodified as luxury goods, rather than valued as social imperatives.

\section{CONCLUSION}

If the goal of a government is to promote a peaceful, prosperous, happy society, then funding the arts is an obvious win. We need to redefine at a political level what prosperity means, and what it should mean in the future. Governments 
should promote individual happiness and creative potential. The arts and creativity are an important part of this equation. As Vannevar Bush noted in his report to President Roosevelt in 1945, it is unlikely that private companies will invest in basic science research [6]. Creativity research in the arts may be classified in the same way - it is complex, hard to quantify and not well understood. Similarly, while there is certainly private funding for the arts in practice, private companies are unlikely to fund the most experimental, risky, avant-garde artwork and this is where government funding is most critical.

Scientists and technologist working with arts and creativity will sometime be forced into making economic arguments in support of this work. While this may not be avoidable, it is important that we are fully aware of the potential negative impacts of such arguments and that we work to offset those by giving voice to the full value of artists and creative work.

Conducting interdisciplinary research between technology, creativity and the arts is highly rewarding. Where else can researchers develop and work with new technology while also being a part of the creative process and the creation of art? I feel grateful to have been able to conduct the research that the NSF Dance.Draw funding enabled. But with the rewards of this work, comes the responsibility of fully respecting the artists one works with. It has taken me four years to begin to understand what the privileging of science means, how it affects my research and why it is so important to value the arts and the creative experience in the right way.

\section{ACKNOWLEDGEMENTS}

I would like to thank the NSF for their support of the Dance.Draw grant. I would also like to thank all my collaborators on this project, in particular choreographers Sybil Huskey and Melissa Word, and computer scientists David Wilson, Erin Carroll, Berto Gonzalez, Vikash Singh and Nathan Nifong. To all of our dancers: thank-you for your inspiration and your commitment to this work. I would also like to thank Heather Lipford, Linda Candy, Kaz Grace, Dan Boisvert, Michael Kelly and David England for their immensely helpful feedback on this paper.

\section{REFERENCES}

1. Allen, T., Tainter, J. A., Pires, J. C., and Hoekstra, T. W. Dragnet ecology-just the facts, ma'am: The privilege of science in a postmodern world. BioScience 51, 6 (2001), 475-485.

2. Amabile, T. M. Creativity and innovation in organizations. Harvard Business School, 1996.

3. Atkinson, R. C. The golden fleece, science education, and US science policy. Proceedings of the American Philosophical Society 143, 3 (1999), 407-417.

4. Balfour, B. Hot flashes, dead bugs, and cocaine for monkeys: The 10 worst federal stimulus projects in North Carolina, 2010. http://www.nccivitas.org/2010/hot-flashes-dead-bugsand-cocaine-monkeys-10-worst-federal-st/.
5. Bell, L. A., and Desai, D. Imagining otherwise: Connecting the arts and social justice to envision and act for change: special issue introduction. Equity \& Excellence in Education 44, 3 (2011), 287-295.

6. Bush, V. Science, the endless frontier: A report to the president on a program for postwar scientific research. National Science Foundation, 1945.

7. Can You Relate? Rape prevention tips, 2013. http://canyourelate.org/2011/05/24/rape-preventiontips/.

8. Carroll, E., Latulipe, C., Fung, R., and Terry, M. Creativity factor evaluation: Towards a standardized survey metric for creativity support. In Proceedings of Creativity \& Cognition, ACM (New York, NY, USA, 2009), 127-136.

9. Carroll, E., Lottridge, D., Latulipe, C., Singh, V., and Word, M. Bodies in critique: A technological intervention in the dance process. In Proceedings of CSCW 2012, ACM Press (2012).

10. Carroll, E. A., and Latulipe, C. Triangulating the personal creative experience: self-report, external judgments, and physiology. In Proceedings of Graphics Interface 2012, Canadian Information Processing Society (Toronto, Ont., Canada, 2012), 53-60.

11. Centre for Economics and Business Research. The contribution of the arts and culture to the national economy, 2013. http://www.artscouncil.org.uk/adviceand-guidance/browse-advice-and-guidance/contributionarts-and-culture-national-economy.

12. Coburn, T., and McCain, J. Summertime blues: 100 stimulus projects that give taxpayers the blues, 2010. http://media.wcnc.com/documents/080310GOPStimulusReport.pdf.

13. Cohen, T. GOP senators list what they say are the 100 worst stimulus projects, 2010. http://www.cnn.com/2010/POLITICS/08/03/senators.stimulus.spending/index.html.

14. Csikszentmihaly, M. Flow: The Psychology of Optimal Experience. Harper \& Row Publishers, New York, 1990.

15. Csikszentmihaly, M. The creative personality.

16. Davies, C., and Sarpong, D. The epistemological relevance of the arts in foresight and futures studies. Futures (2012).

17. Desai, D., Hamlin, J., and Mattson, R. History as art, art as history: Contemporary art and social studies education. Routledge, 2009.

18. Florida, R. The rise of the creative class and how it's transforming work, leisure, community and everyday life (paperback ed.), 2004.

19. Gibson, C., and Kong, L. Cultural economy: a critical review. Progress in human geography 29, 5 (2005), 541-561. 
20. Gonzalez, B., Carroll, E., and Latulipe, C. Dance-inspired technology, technology-inspired dance. In Proceedings of NordiCHI 2012, NordiCHI '12, ACM (New York, NY, USA, 2012), 398-407.

21. Hatfield, E. The golden fleece award: Loves labours almost lost. The Observer 19 (2006), 16-17.

22. Jackson, T. Prosperity without growth: Economics for a finite planet. Routledge, 2012.

23. Jaques, E. Work, creativity, and social justice. 1970.

24. Kaufman, J. C., and Beghetto, R. A. Beyond big and little: The four c model of creativity. Review of General Psychology 13, 1 (2009), 1.

25. Kelly, M., et al. Encyclopedia of aesthetics. Oxford University Press Oxford, UK, 1998.

26. Latulipe, C., Carroll, E., and Lottridge, D. Evaluating longitudinal projects combining technology with temporal arts. In Proceedings of CHI 2011, ACM (2011), 1835-1844.

27. Latulipe, C., Carroll, E., and Lottridge, D. Exploring the measurement and use of audience engagement data in the performing arts. In Proceedings of CHI 2011, ACM (2011), 1845-1854.

28. Latulipe, C., Wilson, D., Gonzalez, B., Harris, A., Carroll, E., Huskey, S., Word, M., Beasley, R., and Nifong, N. Soundpainter. In Proceedings of Creativity \& Cognition 2011, ACM (New York, NY, USA, 2011), 439-440.

29. Latulipe, C., Wilson, D., Huskey, S., Gonzalez, B., and Word, M. Temporal integration of interactive technology in dance: creative process impacts. In Proceedings of Creativity \& Cognition 2011, ACM (2011), 107-116.

30. Latulipe, C., Wilson, D., Huskey, S., Word, M., Carroll, A., Carroll, E., Gonzalez, B., Singh, V., Wirth, M., and Lottridge, D. Exploring the design space in technology-augmented dance. In Extended Abstract Proceedings of CHI 2010 (New York, NY, USA, 2010), 2995-3000.

31. Lord, C. Art and happiness: New research indicates 4 out of 6 happiest activities are arts-related, 2011. http://www.artsjournal.com/newbeans/2011/12/art-andhappiness-new-research-indicates-4-out-of-6-happiestactivities-are-arts-related.html.

32. Luebke, B. Bill gives students real choice in education. http://www.nccivitas.org/2013/bill-gives-students-realchoice-in-education/.

33. McCarthy, K. F., Ondaatje, E. H., Zakaras, L., and Brooks, A. Gifts of the muse: Reframing the debate about the benefits of the arts. Rand Corporation, 2001.

34. Mervis, J. US lawmaker proposes new criteria for choosing NSF grants, 2013. http://news.sciencemag.org/scienceinsider/2013/04/uslawmaker-proposes-new-criteri-1.html.

35. Meyer, R. The Jesse Helms theory of art. October (2003), 131-148.
36. Montgomery, J. Beware the creative class. Creativity and wealth creation revisited. Local Economy 20, 4 (2005), 337-343.

37. Morgan, M. K. Conflict and confusion: What rape prevention experts are telling women. Sexual Coercion and Assault 1, 5 (1986), 160-168.

38. National Endowment for the Arts. National Endowment for the Arts appropriations history. http://www.nea.gov/about/budget/AppropriationsHistory.html.

39. NewsChannel 36 Staff. Dancing stimulus project has critics, 2010. http://www.wcnc.com/home/DancingStimulus-Project-Has-Critics-97677354.html.

40. Proposal Exponent. Federal R\&D funding: Quick agency profiles.

41. Singh, V., Latulipe, C., Carroll, E., and Lottridge, D. The choreographer's notebook - a video annotation system for dancers and choreographers. In Proceedings of the 2011 Conference on Creativity \& Cognition, C\&C '11 (New York, NY, USA, 2011), 197-206.

42. Stacey, K. Maria Miller queries art for arts sake, 2013. http://www.ft.com/cms/s/0/0f32ce5e-ac38-11e2-9e7f00144feabdc0.html.

43. Stuckey, H. L., and Nobel, J. The connection between art, healing, and public health: A review of current literature. Journal Information 100, 2 (2010).

44. Tainter, J. The collapse of complex societies. Cambridge University Press, 1990.

45. The Huffington Post. Is federal money the best way to fund the arts? Join the debate, 2012. http://www.huffingtonpost.com/2012/05/01/.

46. Thomas Investigative Publications. Rape prevention and safety tips through a rapist's eyes, 2013. http://www.pimall.com/nais/rapepreventiontips.html.

47. Tomlinson, B., Silberman, M. S., Patterson, D., Pan, Y., and Blevis, E. Collapse informatics: augmenting the sustainability \& ICT4D discourse in HCI. In Proceedings of CHI 2012, CHI '12, ACM (New York, NY, USA, 2012), 655-664.

48. Turkle, S. Alone together: Why we expect more from technology and less from each other. Basic Books (AZ), 2012.

49. United States Congress. American Recovery and Reinvestment Act of 2009, 2013. http://www.gpo.gov/fdsys/pkg/BILLS$111 \mathrm{hr} 1 \mathrm{enr} / \mathrm{pdf} / \mathrm{BILLS}-111 \mathrm{hr}$ lenr.pdf.

50. Vines, J., Thieme, A., Comber, R., Blythe, M., Wright, P., and Olivier, P. HCI in the press: Online public reactions to mass media portrayals of HCI research. In Proceedings of CHI 2013, ACM (New York, NY, USA, 2013).

51. Wisconsin Historical Society. Golden fleece awards, 1975-1987. http://content.wisconsinhistory.org/cdm/ref/collection/tp/id/70852. 